\title{
Interaction of Opiate Peptide and Noradrenalin Systems: Light Microscopic Studies
}

\author{
S. J. WATSON, C. W. RICHARD III*, R. D. CIARANELLO* AND \\ J. D. BARCHAS* \\ Mental Health Research Institute, University of Michigan, Ann Arbor, MI 48109 \\ and \\ *Department of Psychiatry, Stanford University Medical Center, Palo Alto, CA 94305
}

Received 7 March 1980

\begin{abstract}
WATSON, S. J., C. W. RICHARD III, R. D. CIARANELLO AND J. D. BARCHAS. Interaction of opiate peptide and noradrenalin systems: Light microscopic studies. PEPTIDES 1(1) 23-30, 1980.-In this light microscopic immunocytochemical study $\beta$-Endorphin ( $\beta$-END), leu-enkephalin and dopamine- $\beta$ hydroxylase (DBH) antisera are used to obtain an overview of the interaction of the noradrenergic and opiate peptide systems in brain. Serial brain areas were analyzed for DBH and then for $\beta$-END or leu-enkephalin. Several areas were evaluated for cell and fiber interactions between these systems. The areas of richest possible contact between $\beta$-END and DBH positive systems include the rostral locus coeruleus region, the periaqueductal grey, possibly the dorsal thalamus, the paraventricular hypothalamus and the arcuate nucleus. Enkephalin cells and fibers were seen surrounding the locus coeruleus throughout its length with a few fibers in the nucleus itself.
\end{abstract}

Noradrenalin Enkephalin $\quad \beta$-Endorphin $\alpha$-MSH Brain Anatomy Immunocytochemistry

OVER the last several years there have been many immunohistochemical studies of the enkephalin $[6,7,10,11$, $15,16,23,26]$ and $\beta$-END/ACTH/ $\alpha$-MSH $[3,4,12,13,17$, $19,20,21,22,24,25]$ neuronal systems in rat brain. These general descriptions of the enkephalin and $\beta$-END systems have often mentioned the contiguity of these opiate peptides to the nucleus locus coeruleus or to the ascending catecholamine bundles. Aside from general regional statements, there have been autoradiographic studies of the locus coeruleus demonstrating opiate receptors on the cells of that nucleus [2,14]. In an extension of the autoradiographic studies, Bird et al. [2] iontophoretically applied morphine sulfate to the locus coeruleus and demonstrated decreased firing of those neurons. Recently, Gold et al. [8] provided pharmacological support for a linkage between the opiate system and the noradrenergic locus coeruleus system. They have been able to demonstrate that many of the signs of the opiate abstinence syndrome are mediated via the locus system and, further, that $\alpha$-noradrenergic blockade inhibits signs of opiate withdrawal.

Finally, in studies of electrical stimulation-produced analgesia and its relationship to the endogenous opioid systems, Akil et al. [1] have shown a reciprocal relationship between SPA and noradrenalin. Taken as a whole, these data were seen as suggesting a relatively intimate connection of the enkephalin and/or $\beta$-END/ $\alpha$-MSH systems with the locus coeruleus system.

In this paper we employ light microscopic immunohistochemical techniques to study the relationship between the noradrenalin and $\beta$-END/ $\alpha$-MSH systems. We have empha- sized the study of the cell-containing areas of one system with respect to the fibers of the other system (that is, noradrenalin fibers near the $\beta$-END/ $\alpha$-MSH cells and vice versa). Sections were also taken along the fiber tracks and some terminal areas for study of an interaction of the noradrenalin and $\beta$-END $/ \alpha$-MSH fiber systems. That is, the periaqueductal grey area, the medial forebrain bundle, the periventricular thalamus, the paraventricular nucleus of hypothalamus and the supraoptic nucleus were studied in detail (see Fig. 1). By choosing these areas for study it was possible to highlight possible areas of interaction between these two major systems and to determine which areas are appropriate for future study. Finally sections through the locus coeruleus were studied for the interaction of noradrenalin and enkephalin systems.

\section{METHOD}

Immunocytochemical Technique

The immunocytochemical techniques used in this paper are as described elsewhere [22,24]. In general, 180 gram male Sprague-Dawley rats were anesthetized with $50 \mathrm{mg} / \mathrm{kg} \mathrm{Nem}$ butol, the chest opened, the vascular system flushed with $100 \mathrm{mls}$ cold saline and a canula inserted in the aorta and tied in place. Perfusion was carried out with a paraformaldehyde $(4 \mu \mathrm{g} / 100 \mathrm{ml})$ phosphate buffer $(0.1 \mathrm{M})$ at $4^{\circ} \mathrm{C}$ using $120 \mathrm{~mm}$ $\mathrm{Hg}$ pressure for 30 minutes. The brain was rapidly removed, blocked and placed in fresh perfusate for two hours. It was then changed to $10 \%$ sucrose-phosphate buffer overnight and frozen onto cryostat chucks with liquid nitrogen. The blocks 
were kept frozen at $-90^{\circ} \mathrm{C}$ until sectioning. Ten $\mu \mathrm{m}$ sections were cut at $-20^{\circ} \mathrm{C}$ on a Tissue Tek cryostat, picked up on gelatin-coated glass slides and again stored at $-90^{\circ} \mathrm{C}$.

Sections were air dried for thirty minutes and then covered with primary antiserum diluted in $0.3 \%$ tritonphosphate buffered saline. They were incubated for one hour at $37^{\circ} \mathrm{C}$ and then overnight at $4^{\circ} \mathrm{C}$. After three ten-minute washes in phosphate buffered saline (PBS) they were covered with either goat-anti-rabbit IgG-FITC or goat-antirabbit IgG tetramethyl rhodamine (TMR) (both from Cappel Laboratories, Downington, PA) for one hour at $37^{\circ} \mathrm{C}$. The sections were again washed for thirty minutes, coverslipped with glycerol-bicarbonate solution and viewed under a Leitz Orthoplan microscope using an Epi-illuminator and Fluorescein or Rhodamine filters.

\section{Photography}

Color slides were made using Kodak E-6 film developed at ASA 800. For comparison purposes some areas were photographed for FITC (green), then TMR (red) and finally double-exposed FITC and TMR. Thus it was possible to record each fluorescence color alone and the relationship of the two.

\section{Antisera}

Anti-Dopamine- $\beta$-hydroxylase antiserum was obtained as described elsewhere [5]. The antigen produced a single band on Poly Acrylamide Gel Electrophoresis (PAGE). Rabbits were injected IM with $10 \mu \mathrm{g} \mathrm{DBH}$ at monthly intervals resulting in an antibody usable at $1 / 200$ dilution for rat immunohistochemistry.

Anti-leu-enkephalin antiserum [18] was obtained from rabbits immunized against a leu-enkephalin-gluteraldehyde-BSA complex at monthly intervals. At the $1 / 200$ dilution used in this study it is $<10 \%$ cross-reactive with metenkephalin and shows no cross-reactivity with $\beta$-END or $\beta$-Lipotropin ( $\beta$-LPH). All incubations were carried out in the presence of $10 \mu \mathrm{m}$ met-enkephalin peptide.

Anti- $\beta$-Endorphin antiserum was a generous gift of $\mathbf{R}$. Mains and B. Elipper (Univ. of Colorado). It was obtained in rabbits immunized against a $\beta$-END ${ }_{1-4}$-carbodiimide-BSA complex (Melinda). This antiserum is used at $1 / 500$. It is completely cross-reactive with $\beta$-LPH but not cross-reactive with met- or leu-enkephalin.

Colchicine Pretreatment. In order to enhance the visualization of enkephalin and $\beta$-END/ $\alpha$-MSH cells, a few animals were pretreated with colchicine. They were anesthetized with ether, their skulls drilled just behind and lateral to bregma and a canula inserted. Each animal was given 50 $\mu \mathrm{g}$ colchicine in $50 \mu \mathrm{l}$ saline over $30 \mathrm{sec}$. The skull was closed with bone wax and the animal allowed to recover 48 hours prior to sacrifice as above.

\section{Controls}

$\beta$-END and Leu-enkephalin antisera were blocked by 1 $\mu \mathrm{m}$ excess peptide. Controls for DBH activity were carried out with non-immune rabbit serum. All controls were appropriately negative.

\section{Comparison of Antigens in Tissue Sections}

Two methods of comparison were carried out.

Serial Section. In this approach several $10 \mu \mathrm{m}$ sections were cut in series so that each could be stained for different antigens. For example, in studies of fiber areas such as the periventricular thalamus (six serial sections), sections 1,3 and 5 were stained for DBH and 2, 4 and 6 for $\beta$-END.

Same Section. Several studies were carried out in the same section staining for two separate antigens. Because all the antisera used were from rabbit a precise sequence was followed. That is, the fiber system was always stained with FITC, it was photographed and then followed by the stain for the cell group with TMR. For example, it was possible first to stain for enkephalin fibers (and some cells) in the locus coeruleus sections with FITC (green), to photograph the area and then to stain for DBH cells with TMR (red), then to rephotograph the area. Further, by inserting the FITC filter it was possible to photograph only enkephalin (green) and then to photograph DBH (red) with the TMR filter. In the periarcuate region of hypothalamus the DBH fibers were FITC stained first and then $\beta$-END cells were TMR stained.

\section{RESULTS}

In general there are several possible areas of interaction between the $\beta$-END/ $\alpha$-MSH system and the noradrenergiclocus coeruleus system in rat brain. Both major cell areas appear to be closely involved in fibers from the other system. Further, several bundle and terminal areas exhibit both immunoreactivities, also leading to the hypothesis of interaction at these points.

The results will be presented beginning at the level of the locus coeruleus, moving in rostral fashion (see Fig. 1).

At the level of the locus coeruleus (L.C.), $\beta$-END-Like Immunoreactivity ( $\beta E L I)$ was most prominent around the rostral pole of the nucleus. Figure 2 demonstrates a $10 \mu \mathrm{m}$ serial section study using $\beta$-END (2A) and DBH antisera (2B). There are a few fibers in the L.C. proper (Fig. 7A) but many surrounding it, intermixed with the noradrenalin fiber bundle. A few $\beta E L I$ fibers could be seen lateral to the locus near DBH-positive fibers in the $\mathrm{n}$. parabrachialis.

Moving rostrally to the periaqueductal grey area (PAG), both systems exhibit heavy fiber bundles in close proximity. In Figure $3 \mathrm{~A}$ the $\beta E L I$ is seen as a bundle in the ventrolateral PAG. In Figure 3B DBHLI is seen in a very similar location in the PAG. The DBH bundle overlaps in part with the $\beta$-END positive bundle but is slightly more ventrolaterally displaced.

At the level of the posterior hypothalamus there is no clear patterning of $\beta E L I$ related to the medial forebrain bundle (nor to the substantia nigra). However, Fig. 4 shows that $\beta E L I$ (4A) and DBHLI (4B) are intimately associated in the periventricular nucleus of thalamus. It is not clear that DBHLI in this nucleus is always associated with noradrenergic fibers. Hokfelt et al. [9] have shown many of these fibers to be positive for the epinephrine synthesizing enzyme Phenylethanolamine-N-methyl-Transferase (PNMT).

At the level of the mid-arcuate the $\beta$-END/ $\alpha$-MSH cells are visible after colchicine pretreatment. In Fig. 5A the $\beta$-END stained cells are shown, and in Fig. 5B are the DBH fibers. This is the same section stained twice, first for $\mathrm{DBH}$ fibers, photographed and then stained for $\beta$-END (cells) and rephotographed. A similarly prepared section can be seen in color Fig. 7B. Note the closeness of the DBH fibers to the $\beta$-END perikarya. In other sections there is a striking coincidence of DBH fibers in the arcuate nucleus in the region of $\beta$-END cells; that is, both show very similar patterns within the arcuate nucleus. 


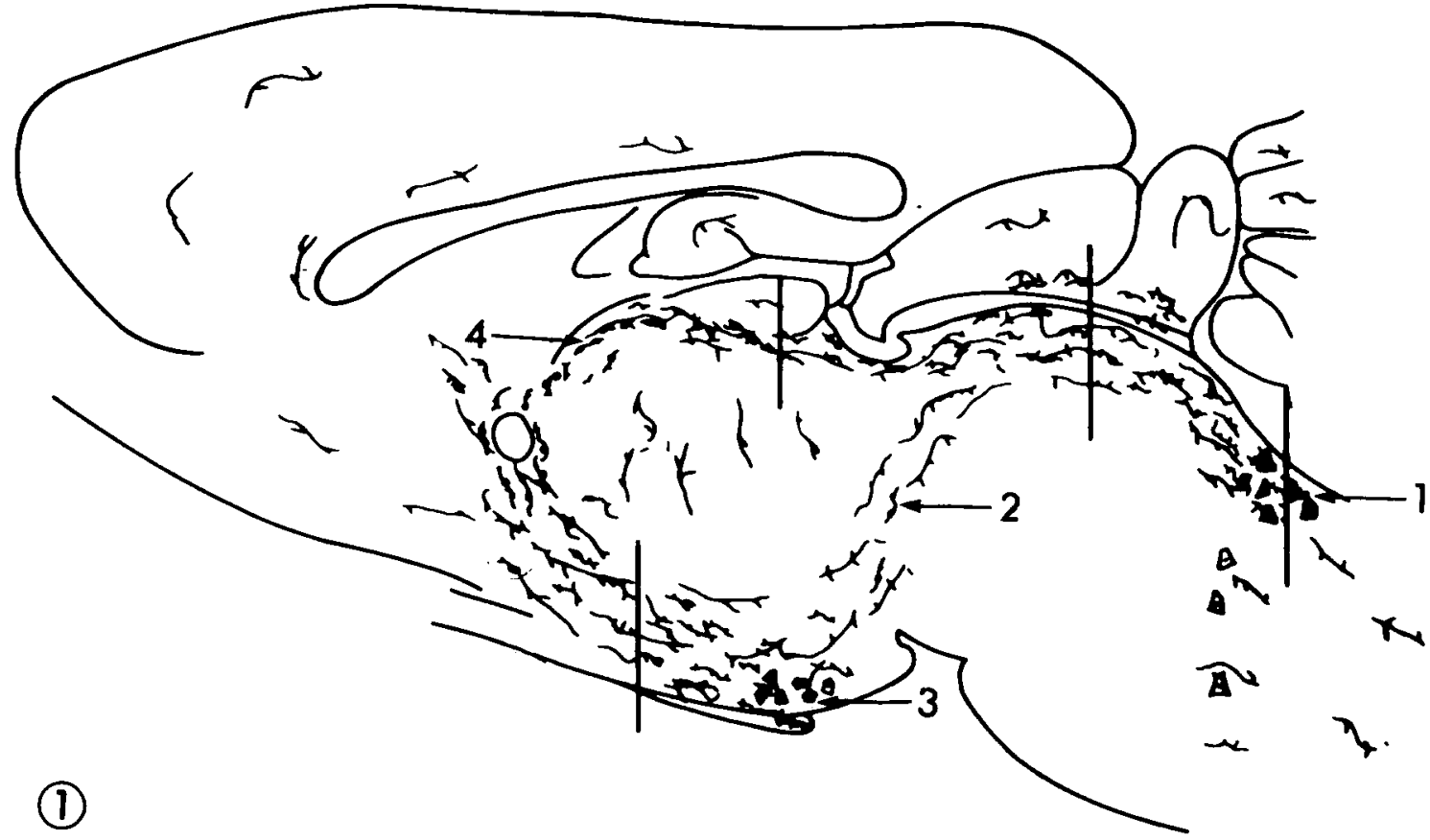

FIG. 1. Parasagital schematic drawing of the locus coeruleus and $\beta$-END/ $\alpha$-MSH systems in rat brain. Number 1 points to locus coeruleus cells. Its fibers flow rostrally through the midbrain and descend into hypothalamus (no. 2 ), then through it to many other structures. A branch is thought to come from the midbrain into the medial thalamus. Number 3 points to the $\beta$-END/ $\alpha$-MSH cell groups in the arcuate region of hypothalamus. Its fibers flow rostrally towards septum and anterior commissure. They then turn caudally through dorsal thalamus (no. 4), back through the brain towards the locus coeruleus. The vertical bars represent some of the levels at which the interaction of these two systems have been analyzed.
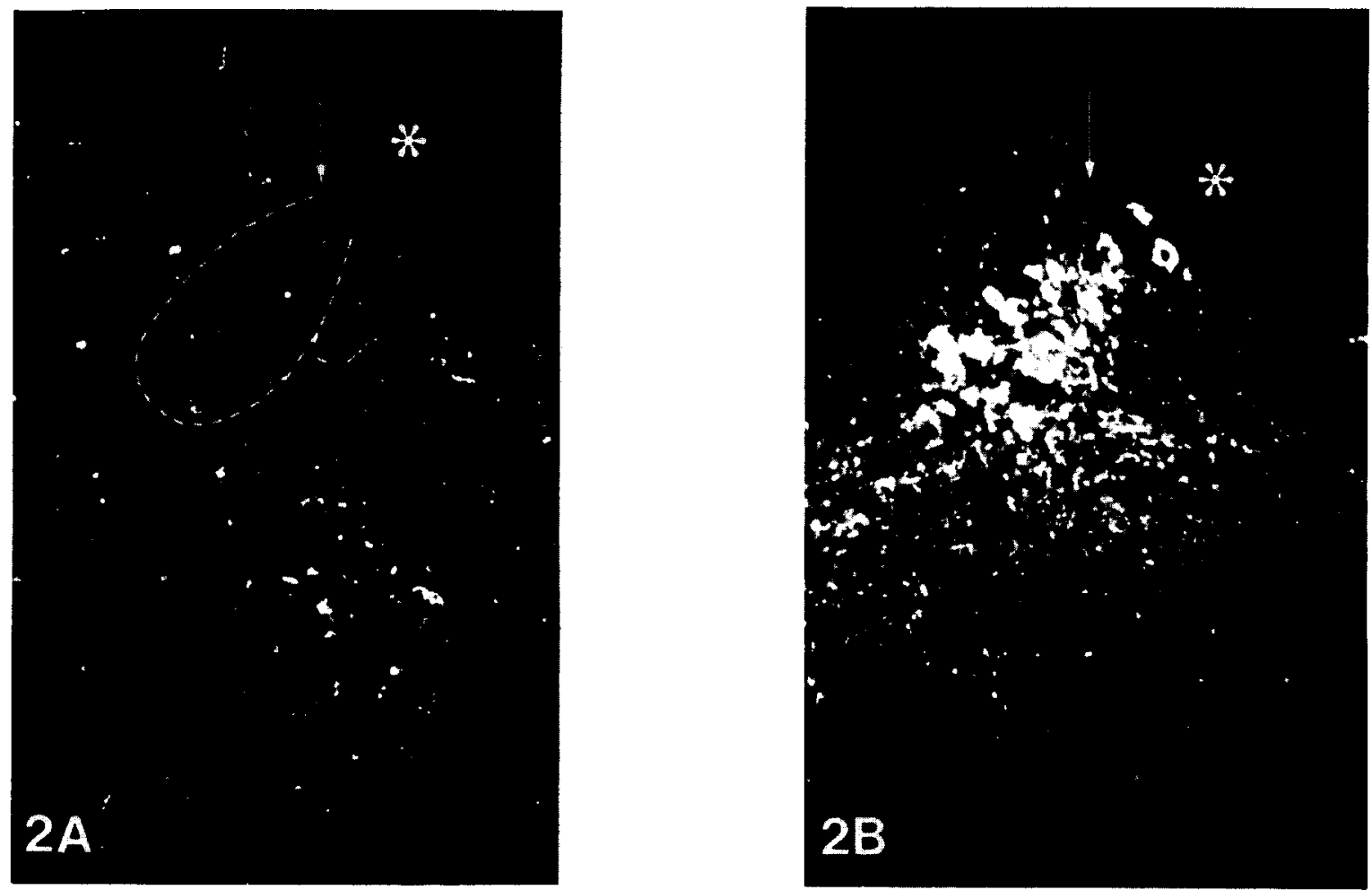

FIG. 2. Serial $10 \mu \mathrm{m}$ sections through the locus coeruleus. Panel A is stained with anti- $\beta$-END antisera and shows several fibers and the bundle in cross section. Panel B shows the next $10 \mu \mathrm{m}$ section stained with anti-DBH antiserum and shows the rostral tip of locus coeruleus and associated fibers. The larger circle in panel A marks the approximate location of DBH cells. It can be seen that $\beta$-END fibers in panel A and DBH processes in panel B often run together. An asterisk indicates the fourth ventricle and the arrow shows common landmarks. $X=225$. 

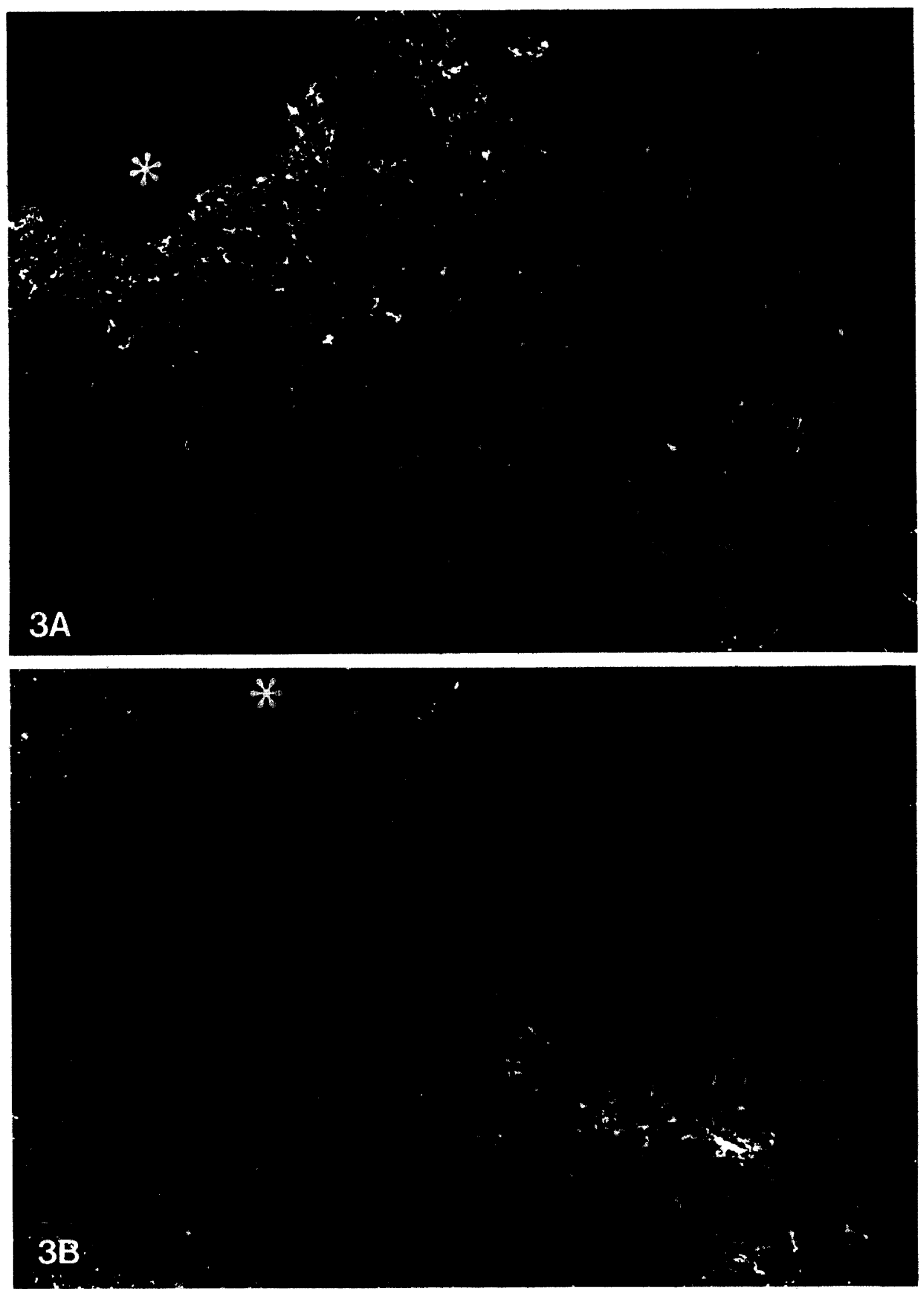

FIG. 3. Serial $10 \mu \mathrm{m}$ sections through the caudal midbrain (panel A, $\beta$-END stained; panel B, DBH stained). The $\beta$-END bundle tends to run closer to the aqueductal surfact, whereas the DBH bundle tends to run more ventral laterally. It can still be seen that, at this level as well as others, the two bundles have many points of potential contact. Big star is in the aqueduct; small star is in a common vessel. $\mathrm{X}=150$. 

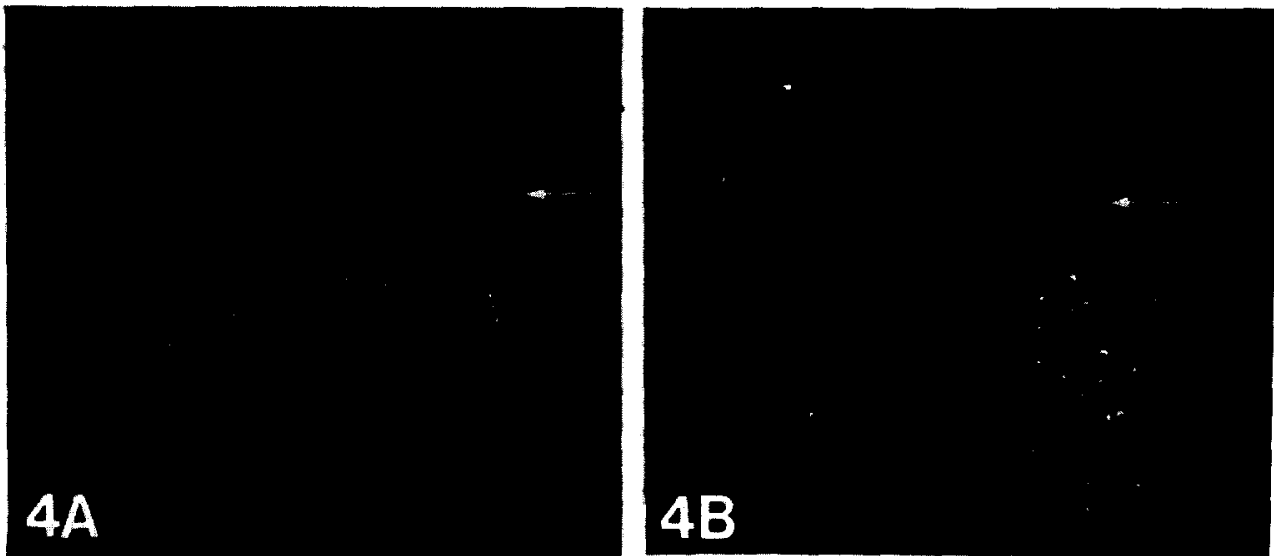

FIG. 4. Serial $10 \mu \mathrm{m}$ sections through the periventricular nucleus of the thalamus (panel A, $\beta$-END stained; panel B stained with $\mathrm{DBH}$ ). The $\beta$-END bundle is found in the dorsal portion of that nucleus whereas the DBH fibers are found throughout its extent. Note that both bundles have symmetrical paired components. Although the two distributions are not identical, it can be seen that $\beta$-END could have extensive contact with the dorsal portion of the $\mathrm{DBH}$ bundle. Arrows point to common vessel. $\mathrm{X}=200$.

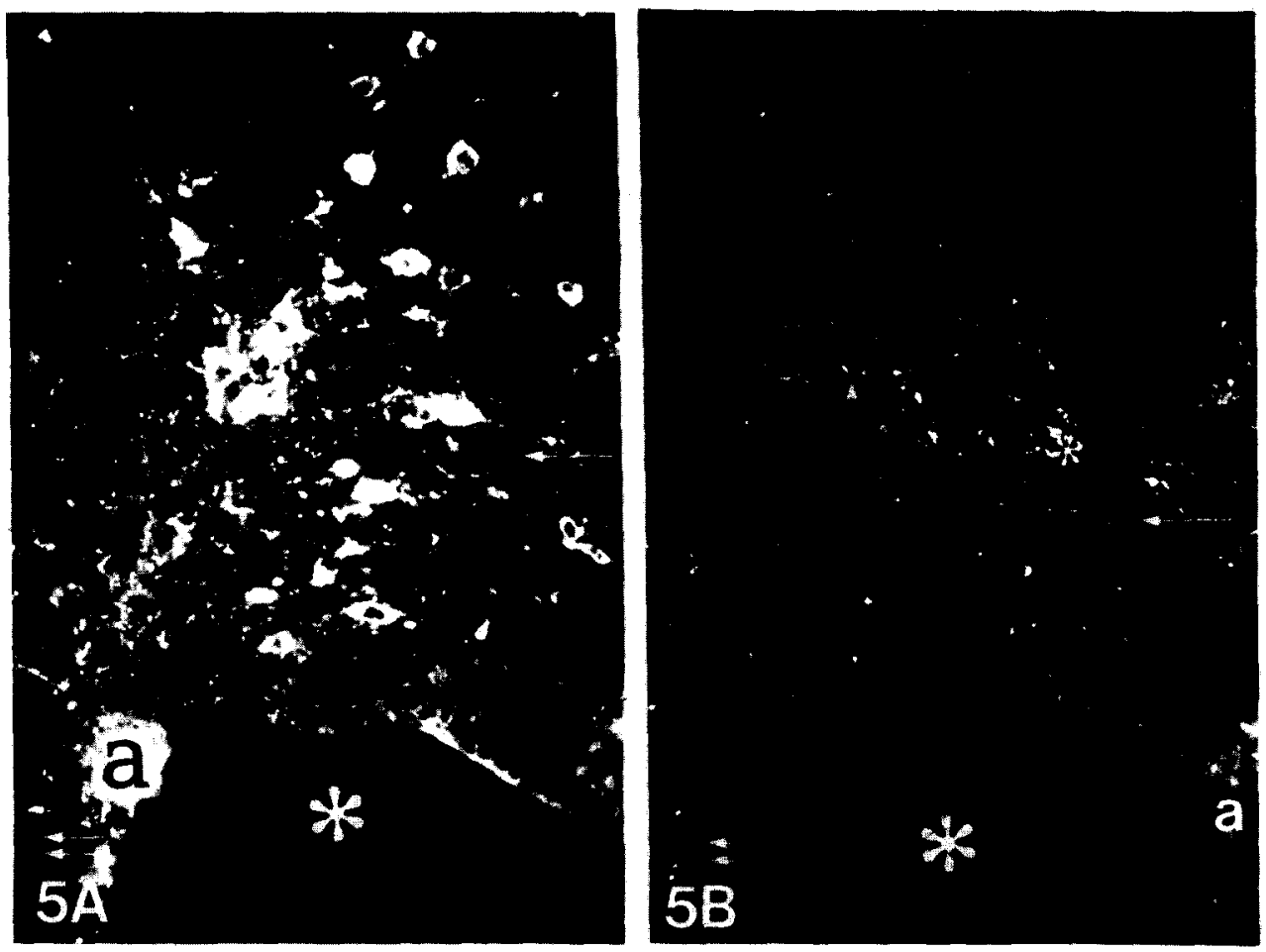

FIG. 5. Double staining of the same $10 \mu \mathrm{m}$ section in the arcuate nucleus with $\beta$-END (panel $A$ ) and DBH (panel B). As described in the text, DBH fibers (panel B) were first stained and photographed, followed by a restaining of the section with ant $\beta$-END and a second photograph. The single arrow points to a vessel in both photographs. The small (right center) asterisk in panel $B(D B H)$ approximates the $\beta$-END cell in panel $A$. Note that the DBH positive fibers in panel $B$ are in the neighborhood of that cell. The small diamond in panel $\mathrm{B}$ is near the location of $\beta$-END positive cells and DBH positive fibers. Double arrow points ventrally. The large asterisk marks the third ventricle. The small letters (a) indicate areas of artifact. $X=225$. 

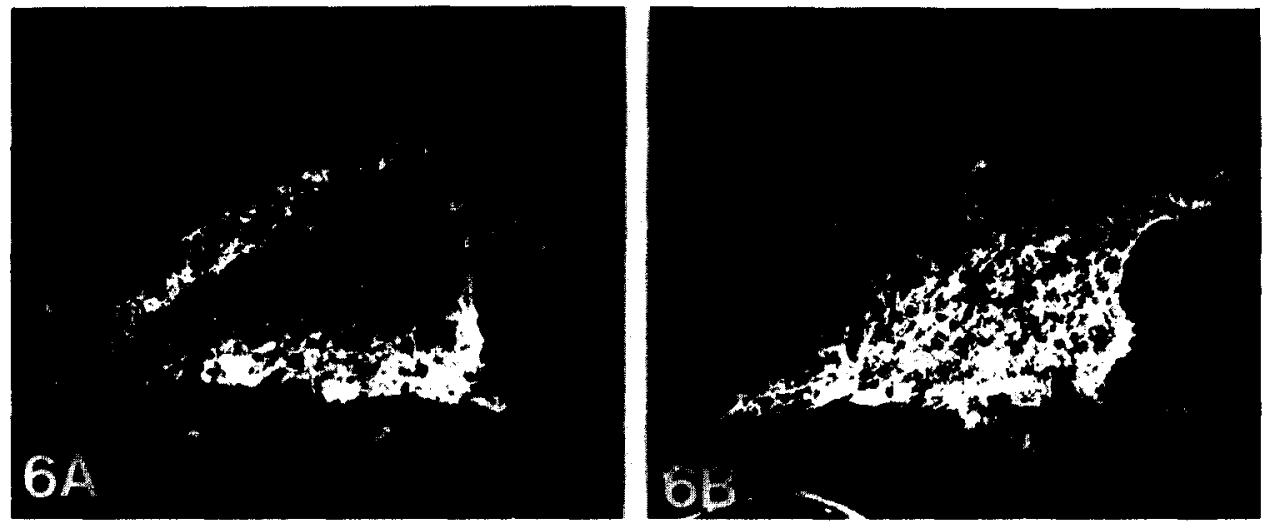

FIG. 6. Serial $10 \mu \mathrm{m}$ sections through the supraoptic nucleus (panel A stained for $\beta$-END; panel B stained for $\mathrm{DBH}$ ). These photos were taken to demonstrate the heterogeneity in some of the final projections of these two systems. $X=200$.

Finally, Fig. 6 shows that this relationship between DBH and $\beta$-END positive systems does not hold in the supraoptic nucleus, as seen in Figs. 6A ( $\beta$-END) and 6B (DBH).

Figures $7 \mathrm{C}$ and $7 \mathrm{D}$ show the results of the study of leuenkephalin-DBH interaction at the level of the locus coeruleus in the same $10 \mu \mathrm{m}$ sections. Enkephalin positive fibers surround the L.C. throughout its length and occasionally penetrate the nucleus inself (7C). Several enkephalin positive cell groups were seen in the $n$. parabrachialis, ventral and lateral to the L.C. (7D).

\section{DISCUSSION}

The general impression one gets from this study is of frequent possible contact between the noradrenergic-locus system and the $\beta$-END/ $\alpha$-MSH system. Both cellular areas are invested with fibers from the other system; and both fiber systems appear to be positioned for frequent contact. However, a closer look will reveal that the nature and extent of the proposed interrelationship is more complex than originally hypothesized.

At the level of the locus coeruleus $\beta$-END fibers are seen most heavily at the rostral pole of that nucleus, whereas leu-enkephalin cells and fibers occur throughout its length. Although there were a few enkephalin fibers seen in the $n$. locus coeruleus itself, most enkephalin cells and fibers and $\beta$-END fibers were seen surrounding that cell group. Figures 2 and 7 (C and D) tend to suggest that the main potential for opiate peptide interaction with noradrenalin is with the NA fibers and processes and not the perikarya themselves.

Moving rostrally to the periaqueductal central grey area the impression of fiber interaction is reinforced (Fig. 3). The descending $\beta$-END $/ \alpha$-MSH bundle and the ascending NA bundle follow an overlapping and often almost identical pathway through the midbrain. However, at the level of the substantia nigra as the norepinephrine bundle flows into the lateral hypothalamus, there is relatively little $\beta$-END $/ \alpha$-MSH activity. The $\beta$-END $/ \alpha$-MSH bundle, rather than flowing out of posterior hypothalamus to PAG, has descended from the periventricular nucleus of thalamus (Fig. 1). Figure 4 reflects the very close relationship the $\beta$-END and DBH positive bundles have in dorsal medial thalamus. However, it is not clear that all the DBH fibers are NA-containing. As mentioned earlier, some may well contain PNMT and therefore be adrenergic fibers. Since the main noradrenergic bundle has moved into lateral hypothalamus and many of the thalamic fibers are PNMT-positive, it would seem that the noradrenalin- $\beta$-END relationship is less clear in thalamus.

As seen in Figure 1, the $\beta$-END $/ \alpha-\mathrm{MSH}$ bundle seems to have come to thalamus via the septo-anterior commisural route from its cells of origin in the arcuate nucleus of hypothalamus. This cell group is immunoreactive for all of the known pieces of proopiocortin (the $31 \mathrm{~K}$ dalton precursor for ACTH, $\alpha$-MSH, $\beta$-LPH, $\beta$-END and a poorly studied $16 \mathrm{~K}$ fragment). When the arcuate nucleus is studied (after colchicine pretreatment) the perikarya appear closely approximated to DBH positive fibers (Fig. 5). A closer examination of these cells and associated processes shows them to be in the midst of the largest DBH fiber concentration in the arcuate nucleus. It is possible that these DBH fibers are also not noradrenalin but epinephrine-containing. The current study did not address the issue.

In sum, this study tends to support the hypothesis of a close relationship between these two systems at several points. Both cell groups (or associated processes) would appear to be closely approximated to fibers of the other system. As the $\beta$-END/ $\alpha$-MSH fiber system descends and the noradrenergic system ascends they have several possible areas for interaction. Not shown in the figures are potential areas of contact such as the paraventricular neucleus of hypothalamus, and the lateral septum. The clearest potential interaction sites appear to be the arcuate nucleus of hypothalamus and an area from the region of the PAG down to the area of the locus coeruleus.

It is possible to hypothesize that the inhibition of noradrenergic cells by opiates occurs via the $\beta$-END receptor system on or near NA processes. From this study it appears likely that enkephalin could provide that inhibitory effect as well. We currently have no evidence to support either hypothesis; nor can we eliminate the possibility that both peptidergic systems inhibit noradrenergic firing. One possible approach would be to study the distribution of several opiate responses in the locus coeruleus, remembering that enkephalin seems to surround the entire nucleus, whereas $\beta$-END is found mainly at the rostral pole.

We currently know very little about the control of brain $\beta$-END/ $\alpha$-MSH neurons. If NA is found to inhibit the arcuate $\beta$-END $/ \alpha$-MSH system, then each system would appear to be able to inhibit the action of the other. Clearly, more thorough work is needed before these questions can be resolved. 

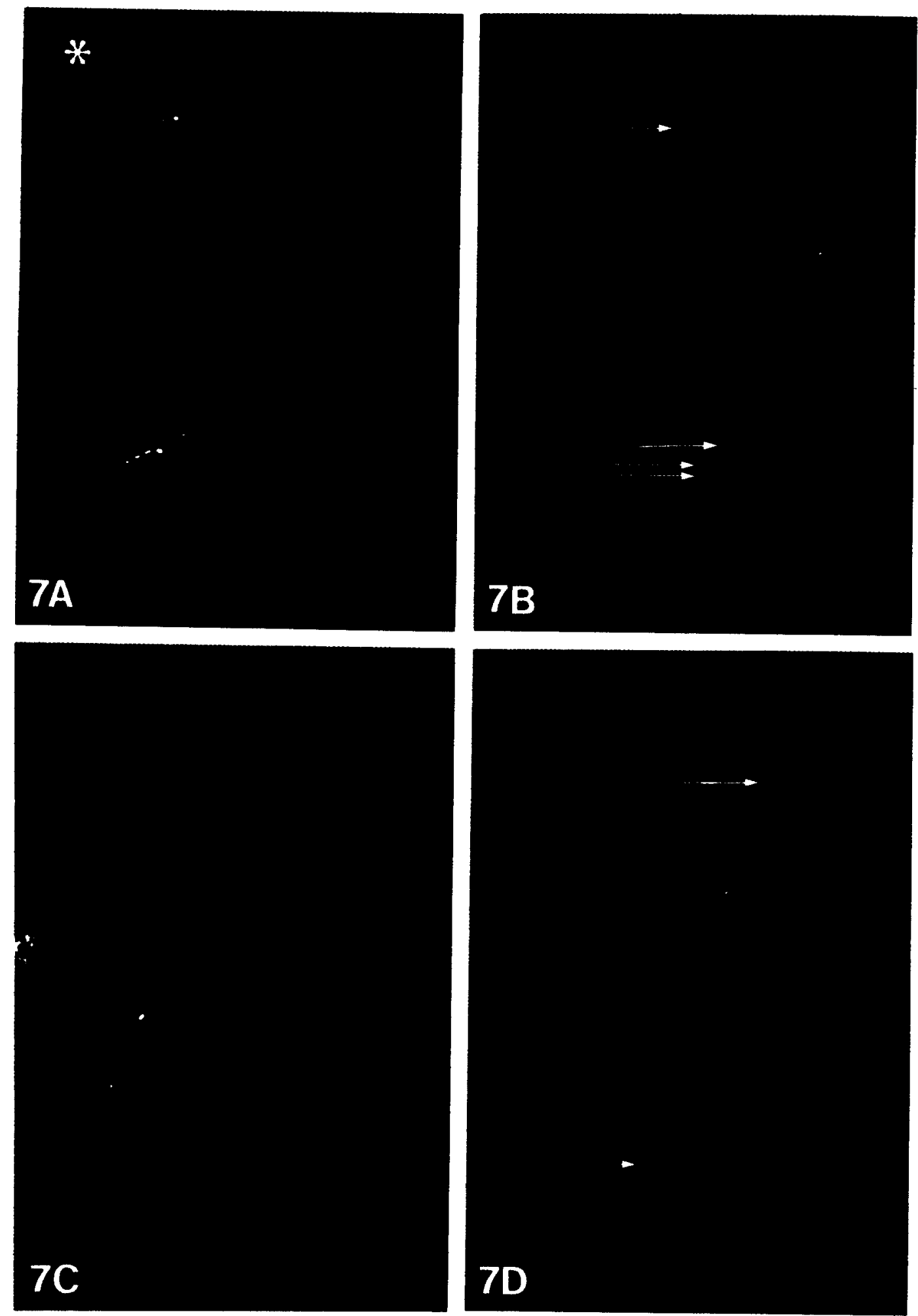

FIG. 7. (A) $10 \mu \mathrm{m}$ section through the locus coeruleus was first stained for $\beta$-END using green FITC (lower panel), photographed and then stained with anti-DBH using red TMR (upper panel). The upper panel is double-exposed with FITC, then TMR filters. It shows the red DBH cells approximated by a yellow-green $\beta$-END fiber. $X=800$.

(B) A similar process to 7A was followed in this $10 \mu \mathrm{m}$ section through the arcuate nucleus. The DBH fibers were stained FITC-green followed by $\beta$-END cells stained with TMR-red. Double exposure produces yellow-red $\beta$-END cells (see arrows) near yellow-green DBH fibers. $X=800$.

(C) $10 \mu \mathrm{m}$ section through the locus coeruleus were first stained for leu-enkephalin (green-FITC), then for DBH cells (red-TMR). Double exposure with proper filters shows the proximity of leu-enkephalin fibers to the DBH bundle and surrounding the nucleus itself (a few fibers are seen in it as well). $X=200$.

(D) A similar preparation to $7 \mathrm{C}$ except in a colchicine pretreated animal ( $50 \mu \mathrm{g}$, icv, 48 hours prior to sacrifice), reveals leu-enkephalin cells-green (arrows) very near the locus DBH cells (red). $X=200$. 
The complex anatomical interactions suggested by this study raise several other questions. It is important to resolve the question of which (if any) of these fiber systems are actually epinephrine-containing. From our data, two areas are particularly unclear in this respect-the arcuate nucleus and periventricular thalamic fibers [9]. In looking at the ascending noradrenalin fiber system some areas seem to have a close relationship with $\beta$-END fibers, whereas others do not. It would be of interest to compare the $\beta$-END relationship to the norepinephrine bundle to that of enkephalin and norepinephrine. Perhaps the relationships of the different peptides to the NE bundle could be shown in local pharmacological susceptibilities. For example, drugs more like $\beta$-END might act in the PAG, whereas more enkephalin-like opiates might act in posterior locus coerulus or the medial forebrain bundle. Finally, a similar study of enkephalin and its relationship to the monoamines is also needed.

Throughout this paper we have alluded to the possibility of contact between two neurotransmitter systems. It is important to remember that this is a correlative study, using light microscopic techniques and, as such, cannot answer such connectivity-synapse questions. It is hoped that this study has suggested areas for detailed light and electron microscopic study aimed at neurotransmitter connectivity.

\section{ACKNOWLEDGEMENTS}

This work was supported in part by NIDA grant No. DA 0226502 (to SJW), grant No. NSF-TCM 7814183, NIMH MH-25998, RSDA No. NIMH MH-00219 (to RDC), and grant No. MH-23861 (to JDB). The authors express their appreciation to Ms. C. Criss for manuscript preparations and R. Beer and R. Thompson for technical assistance.

\section{REFERENCES}

1. Akil, H. and J. C. Liebeskind. Monoaminergic mechanisms of stimulation-produced analgesia. Brain Res. 94: 279-296, 1975.

2. Bird, S. J., S. F. Atweh and M. J. Kuhar. Microiontophoretic study of the effects of opiates on autoradiographically localized opiated receptors. In: Opiates and Endogenous Opioid Peptides, edited by H. W. Kosterlitz, Amsterdam: Elsevier/North Holland Biomedical Press, 1976, pp. 199-204.

3. Bloch, B., C. Bugnon, D. Fellman and D. Lenys. Immunocytochemical evidence that the same neurons in the human infundibular nucleus are stained with anti-endorphins and antisera of other related peptides. Neurosci. Lett. 10: 147-152, 1978. $152,1978$.

4. Bloom, F. E., E. Battenberg, J. Rossier, N. Ling, J. Leppaluoto, T. M. Vargo and R. Guillemin. Endorphins are located in the intermediate and anterior lobes of the pituitary gland, not in the neurohypophysis. Life Sci. 20: 43-48, 1977.

5. Ciaranello, R. D., G. G. Wooten and J. Axelrod. Regulation of dopamine $\beta$-hydroxylase in rat adrenal glands. J. Biol. Chem. 250: 3204-3211, 1975.

6. Cuello, A. C. and G. Paximos. Evidence for a long leuenkephalin striopallidal pathway in rat brain. Nature 271: 178$180,1978$.

7. Elde, R., T. Hokfelt, O. Johansson and L. Terenius. Immunohistochemical studies using antibodies to leucine enkephalin: initial observations on the nervous system of the rat. Neuroscience 1: 349-351, 1976.

8. Gold, M. S., D. C. Redmond and H. D. Kleber. Noradrenergic hyperactivity in opiate withdrawal supported by clonidine reversal of opiate withdrawal. Am. J. Psychiat. 136: 100-102, 1979.

9. Hokfelt, T., K. Fuxe, M. Goldstein and O. Johansson. Immunohistochemical evidence for the existence of adrenalin neurons in the rat brain. Brain Res. 66: 235-251, 1974.

10. Hokfelt, T., R. Elde, O. Johansson, L. Terenius and L. Stein. The distribution of enkephalin-immunoreactive cell bodies in the rat central nervous system. Neurosci. Lett. 5: 25-31, 1977.

11. Jacobwitz, D. M., M. A. Silver and W. G. Soden. Mapping of leu-enkephalin containing axons and cell bodies of the rat forebrain. In: Endorphins in Mental Health Research, edited by E. Usdin. New York: Oxford University Press, 1979, pp. 62-74.

12. Nilaver, G., E. A. Zimmerman, R. Defendini, A. Liotta, D. A. Krieger and M. Brownstein. Adrenocorticotropin and $\beta$-lipotropin in hypothalamus. J. Cell Biol. 81: 50-58, 1979.

13. Pelletier, G., L. Desy, J-C. Lissitszky, F. Labrie and C. H. Li. Immunohistochemical localization of $\beta$-LPH in the human hypothalamus. Life Sci. 22: 1799-1804, 1978.
14. Pert, C. B., M. J. Kuhar and S. H. Snyder. Autoradiographic localization of the opiate receptor in rat brain. In: The Opiate Narcotics: Neurochemical Mechanisms in Analgesia and Dependence, edited by A. Goldstein. New York: Pergamon Press, 1975, pp. 97-101.

15. Sar, M., W. E. Stumpf, R. J. Miller, K. J. Chang and P. Cuatrecasas. Immunohistochemical localization of enkephalin in rat brain and spinal cord. J. comp. Neurol. 182: 17-37, 1978.

16. Simantov, R., M. J. Kuhar, G. R. Uhl and S. H. Snyder. Opioid peptide enkephalin: immunohistochemical mapping in rat central nervous system. Proc. natn. Acad. Sci. U.S.A. 74: 2167$2171,1977$.

17. Sofroniew, M. V. Immunoreactive $\beta$-endorphin and ACTH in the same neurons of the hypothalamic arcuate nucleus in the rat. Am. J. Anat. 154: 283-289, 1979.

18. Sullivan, S., H. Akil, S. J. Watson and J. D. Barchas. Antibodies to enkephalins: coupling of antigens and a specific methionine-enkephalin radioimmunoassay. Commun. Psychopharm. 1: 605-610, 1977.

19. Watson, S. J. $\alpha$-MSH in brain $\beta$-endorphin neurons and other neurons as well. In: Endogenous and Exogenous Opiate Agonists and Antagonists, edited by E. Leong Way. New York: Pergamon Press, 1980, pp. 127-130.

20. Watson, S. J. and H. Akil. Presence of two $\alpha$-MSH positive cell groups in rot hypothalamus. Eur. J. Pharmac. 58: 101-103, 1979.

21. Watson, S. J. and H. Akil. $\alpha$-MSH in rat brain: Occurence within and outside brain $\beta$-endorphin neurons. Brain Res. 182: 217-223, 1980.

22. Watson, S. J., H. Akil, C. W. Richard and J. D. Barchas. Evidence for two separate opiate peptide neuronal systems and the coexistence of $\beta$-lipotropin, $\beta$-endorphin and ACTH immunoreactivities in the same hypothalamic neurons. Nature 275: 226-228, 1978.

23. Watson, S. J., H. Akil, S. O. Sullivan and J. D. Barchas. Immunocytochemical localization of methionine-enkephalin: preliminary observatins. Life Sci. 25: 733-738, 1977.

24. Watson, S. J., J. D. Barchas and C. H. Li. $\beta$-Lipotropin: localization of cells and axons in rat brain by immunocytochemistry. Proc. natn. Acad. Sci. U.S.A. 74: 5155-5158, 1977.

25. Watson, S. J., C. W. Richard and J. D. Barchas. Adrenocorticotropin in rat brain: immunocytochemical localization in cells and axons. Science 200: 1180-1182, 1978.

26. Uhl, G. R., M. J. Kuhar and S. H. Snyder. Enkephalin containing pathway amygdaloid efferents in the stria terminalis. Brain Res, 149: 223-228, 1978. 